\title{
ARTICLE
}

International Journal of Media and Cultural Politics

Special issue on Audiences and the Environment

\section{Blogging on the ice: connecting audiences with climate-change sciences}

Dr EINAR THORSEN, Bournemouth University, ethorsen@bournemouth.ac.uk

\begin{abstract}
Scientists working in Antarctica have recognized the need to counteract problems associated with mainstream media's treatment of the climate-change crisis. For this reason, several of them have assumed the role of citizen journalists in order to report on the effects of global warming first-hand. More specifically, they have chosen to communicate directly with the general public through official or personal blogs. In so doing they are capitalizing on the way the Internet is changing science news and journalism (see Allan, 2009; Trench, 2007). This article draws on an analysis of more than 50 Antarctic blogs published during the International Polar Year (2007-2008), as well as data from e-interviews with a broad selection of bloggers, in order to examine how scientists "on the ice" act as citizen journalists. The article explores the idea of citizen journalism as education and the extent to which the scientists achieve an unmediated form of communication through their blogging efforts. It concludes by suggesting this new form of citizen journalism, beyond raising people's awareness of the climate-change crisis, also signals an important way in which mainstream environmental reporting can be reinvigorated.
\end{abstract}

\section{KEYWORDS}

climate change; science; blogging; citizen journalism; audience interaction

If every kid has a blog, why not every scientist?

(Breana Simmons, Antarctic blogger)

On October 12, 2007, the Nobel Peace prize for that year was awarded in equal parts to the Intergovernmental Panel on Climate Change (IPCC) and Al Gore Jr. "for their efforts to build up and disseminate greater knowledge about man-made climate change, and to lay the foundations for the measures that are needed to counteract such change" (The Norwegian Nobel Committee, 2007). The Norwegian Nobel Committee's intention was "to contribute to a sharper focus on the processes and decisions that appear to be necessary to protect the world's future climate" (ibid). This was also the objective of the UN Secretary General, Ban Ki-moon, when he visited Antarctica only one month later, in November 2007, "as a messenger of early warning" to "observe the impact of Global Warming" (Ki-moon, 2007). He was the first UN Secretary General to have set foot on the continent, further demonstrating the level of international attention that the crisis was gaining. In his own words:

This is not scare-mongering. I am not trying to frighten you. [...] These things should alarm us all. Antarctica is a natural lab that helps us understand what is happening to our world. [...] It is here where our work, together, comes into focus. We see Antarctica's beauty - and the danger global warming represents, and the urgency that 
we do something about it. I am determined that we shall (Ki-moon, 2007).

Both of these events took place during the International Polar Year (IPY) 2007-2008 ${ }^{\mathrm{i}}$ - an internationally coordinated effort to focus interdisciplinary research on providing a snapshot in time of the polar-regions. The 2007-2008 IPY was the fourth of such initiatives and the first in the age of the Internet - following the previous polar years in 1882-83, 1932-33, and 1957-58. Each of these initiatives had a distinct focus and central to the 2007-2008 IPY research initiatives was the will to further understand both the rate and cause of climate change, by studying the geographical areas where such change can have the most devastating effect - both locally and globally. The recent IPY also provided a focal point for connecting audiences with these scientific endeavours - for example through staged events for news media or organised educational outreach programmes.

In the shadow of high-profile media and public engagement activities there is an expanding network of scientist bloggers, who have assumed the role of citizen journalists in order to report on the effects of global warming first-hand. They have chosen to communicate directly with the general public through official or personal blogs, as a way of mitigating problems traditionally associated with the mainstream media's treatment of the climatechange crisis. In so doing they are capitalizing on the way the Internet is changing science news and journalism (see Allan, 2009; Trench, 2007; Batts et al, 2008). This approach to citizen journalism has become a central part of an educational outreach strategy aimed at connecting Antarctic scientists with members of the public around the globe, including schoolchildren. The ensuing form of dialogue, where they respond to questions put to them on the blog, helps to bridge a perceived disconnect between scientific experts and lay people.

This article draws on an analysis of more than 50 Antarctic blogs published during the International Polar Year (2007-2008), as well as data from e-interviews with a broad selection of these bloggers, in order to examine how scientists "on the ice" act as citizen journalists and connect global audiences with their research. It concludes by suggesting this form of citizen journalism, beyond raising people's awareness of the climate-change crisis, also signals an important way in which mainstream environmental reporting can be reinvigorated.

\section{Science blogging: re-connecting with publics}

Mainstream news organizations have traditionally struggled to report the process of climate change, or indeed science more generally, since it tends to be perceived by journalists to be lacking in spectacle or tangible events that can be easily recast in their news coverage (see Allan, 2009; Carvalho, 2007; Carvalho \& Burgess, 2005; Russell, 2008). It is "one of the most complicated stories of our time," Wilson (2000) argued, which "is also affected by a number of journalistic constraints, such as deadlines, space, one-source stories, complexity and reporter education" (Wilson, 2000:206). Reporting of the climate change crisis, therefore, is often visualized through events staged by political figures or celebrities, some of whom travel to remote areas of the world so that they can be seen to be bearing witness to a crisis otherwise imperceptible to the human eye.

The climate change crisis has been steadily making its way up the news agenda due to what Neverla (2008) described a "climatic turn." In highlighting research that indicates there have been both quantitative and qualitative shifts in media coverage on climate change, she 
argued that this improvement has been driven in part by global warming increasingly being associated with a negative framing (e.g., "climate catastrophe") and elite-political figures or celebrities (e.g., Al Gore; the IPCC and its chair, Rajendra Pachauri; the British Prime Minister, David Cameron; or Leonardo DiCaprio), thus fulfilling some of traditional media's news values (see Neverla, 2008:5). However, the science that maps the process of global warming remains largely underreported. Certainly in the case of the British popular press, as Gavin (2007) observed, the crisis has been denied in-depth treatment. More dramatically, in relation to the US press and television, Boykoff and Boykoff (2007) argued that "the mass media can adversely affect the interactions between science, policy, and the public" (2007:1201). Adherence to "the norms of dramatization, personalization, novelty, balance, and authority-order," they contended, has led to "informationally deficient coverage" of global warming and "has helped to create space for the US government to defray responsibility and delay action regarding climate change" (ibid).

Audience behaviors have shifted too, with the Pew Internet Project and Exploratorium in 2006 finding the Internet was a primary source of science news for $20 \%$ of the US population (second only to television), with $59 \%$ of the respondents saying they would turn first to the Internet to find more information about climate change (Horrigan, 2006). The number of people turning to the Internet for science news has likely grown exponentially with the increase in broadband connectivity, as noted by Horrigan (2008), the chief researcher behind the Pew report. In light of this, Ashlin and Jadle (2006) called for environmental scientists to "actively engage in blogging to increase the presence of informed opinions in the blogosphere" (2006:201). For them it was important to ensure "accurate representation of environmental science", but also because the "interactive characteristics of weblogs" afforded new opportunities to solicit feedback and engage in environmental debates. "If environmental scientists ignore online communication platforms such as weblogs," they reflected, "we run the risk of creating a generation of eco-illiterate consumers and voters at a crucial time for the Earth's diminishing resources" (ibid). Batts et al (2008) took this one step further, suggesting that blogs could even act as a "quick forum for public peer review of research" (2008:1837). They called for a more concerted institutional effort within academic research "to facilitate high-quality interactions between blogs, institutions, and readers; and incorporating blogs into meta-conversations within and between institutions" (ibid).

Whilst individual scientists had long experimented with Internet communication, according to Shanahan (2011), the establishment of science blogging networks around 2006 encouraged growth and recognition of the practice. Eventually "seen as an important and valuable form of science communication", science blogging even "spawned international conferences" and "made headlines as a venue for scientific critique" (Shanahan, 2011:903). Colson found that scientists would take up blogging "mainly based on a desire to bypass traditional media" (2011:900). That is,

Most of the scientists who blog think that the quality of science coverage in the traditional media has declined and consider that the media is no longer able to play its role as a watchdog in the world of science. (Colson, 2011: 900)

Such a view chimes with the deficit model of science communication, which implies that there is a dearth in public knowledge about science that is directly connected with inadequacies in how it is being communicated and reported upon. The contention being that members of the public would be more likely to see issues as experts do if they only had a 
greater understanding of the scientific evidence. However, this risks being simplistic in contemporary debates, since, for example, it does not sufficiently account for how different news "frames" connect with audiences. Yet, Bubela et al (2009) contend that "science blogs also engage in strategic framing, with some of the most popular science bloggers blending discussion of science with ideologically driven commentary on politics and religion". In their view, therefore, "these popular blog sites become echo chambers reinforcing deficitmodel assumptions about the public, singling out science literacy as the golden key to winning support" (Bubela et al, 2009: 517). Regardless of such challenges, it is clear that "alternative approaches to science reporting are flourishing online" (Allan, 2009: 282). One central feature of such online communication is connectivity with audiences, making both scientists and scientific research accessible to non-experts.

According to Davis (2008), connecting with audiences also depends on scientists adopting a more accessible style of writing. Traditional scientific writing, Davis contends, has significant advantages in the way it verifies and affirms scientific discovery. Thus the scientific writing can be described in broad terms as "concise", "unambiguous", "complete", and "focused". Yet, its epistemological approach follows a "prescribed method of communicating those results", which "is a poor means of communicating to the nonspecialist". Indeed the results are often "tedious", "incomprehensible to the non-specialist", and "unable to deal with the big picture" (Davis, 2008:150). By contrast, the more popularized form of science writing, features a tone that "is casual and colloquial, encouraging engagement with the reader" (ibid:151). For him the "more-or-less closed system of access" for deciding on scientific funding underpins a process that "has largely removed the public from the Antarctic scientist's radar" (ibid:152). According to Davis,

as Antarctic scientists the responsibility for popularizing our research falls more squarely on our shoulders given the limited access others have to the Antarctic. [...] it is not just what we say, but the way we say it that is important (Davis, 2008:148).

Davis also offered a series of suggestions for scientists to popularize science, including: film / video, installations, books, magazines / newspapers, and online. This article is specifically concerned with the latter, and will now turn to examine how Antarctic scientists are embracing blogging as one way of connecting publics around the globe with environmental sciences.

\section{People and communications in Antarctica}

Antarctica is a hostile, frozen continent without an indigenous population or even national sovereignty ${ }^{\text {ii }}$, the continent being effectively controlled by the Antarctic Treaty System. The original Antarctic Treaty was instigated by the US during the International Geophysical Year (IGY) of 1957-58, aimed at preserving Antarctica "in the interest of all mankind" for "exclusively peaceful purposes", given its "substantial contributions to scientific knowledge resulting from international cooperation in scientific investigations" (The Antarctic Treaty, 1959:2). Signed in 1959 by the twelve countries conducting research in Antarctica at the time, the treaty entered into force in 1961 as the first arms control agreement of the Cold War. Thirty-four countries have since acceded to the treaty, which together with the original twelve, is divided into twenty-eight Consultative Parties and eighteen Non-Consultative Parties who are invited to meetings, but have no decision making powers.

While there are no permanent inhabitants in Antarctica, 28 countries maintain research bases through their respective National Antarctic Programs. There are 38 year-round bases, 
with the South Pole Station and the McMurdo Station, both run by the US Antarctic Program, being the largest. Seasonal-only stations operate during the austral summer months and consist of permanent and temporary facilities, including tent camps and mobile traverses in support of research. The number of scientists and support staff across these stations peaks at approximately 4,000 during summer and falls to around 1,000 during winter. Some 30 nationalities were represented in 2007-2008, with the majority of the population stemming from the United States, Argentina, Russia, Chile, Australia, and the United Kingdom.

The history of Antarctic communication is rich with technological innovation, engendered in part by the extreme weather and distance from other continents. Douglas Mawson broadcast the first radio transmission from the continent in December 1912, with two-way communication between Adélie Land (Antarctica) and Macquarie Island (Australian territory south of Tasmania and New Zealand) established in February 1913. Radio communications were not perfected, however, until Richard E. Byrd's first Antarctic expedition between 1928 and $1930^{\mathrm{iii}}$. These early transmissions relied on Very Low Frequency (VLF) bands and Morse code to convey messages. High Frequency (HF) bands were only put into use after the Second World War, with teleprinters and radiotelephones appearing in the early 1960 s.

Satellite communication was introduced initially through the Inmarsat system in the mid1980 s, which allowed voice and data communications via satellite. However, the system was highly expensive and while bandwidth was much greater than HF communications (300 characters per minute vs 60 characters), this was still seen as too restrictive for modern needs. The world's first dedicated Antarctic satellite communication system was the Australian ANARESAT launched in 1986-1987, which was closely followed by similar systems deployed by other national Antarctic programs. These new satellite communication links provided a much greater bandwidth than any of the previous systems (though some of these remain in place as backup). Used in combination with the Internet, it became possible to communicate more frequently, sharing richer content, and with a greater degree of audience interaction than had previously been possible.

By way of example, the continent was host to some of the very first online journals, precursors to what are now commonly referred to as blogs. Appearing in the latter months of 1993, Dr. Stokers Project Status Reports and the more chatty, informal Dale's Dive Diary (written by Dale Anderson) were online, interactive companions for the Live From ... Other Worlds television series. The team of scientists answered questions via email until February 1994, responding to more than 100 questions - including several on "global climate change" and "global warming" - put to them by schoolchildren back in the United States. The websites exemplify early experimentation with the Internet as a way of reporting on the daily activities of scientists in Antarctica and engaging lay audiences with their research.

\section{Blogging on the ice}

By the time of the International Polar Year (IPY) of 2007-2008, Internet access had evolved to become an integral resource for the scientific community in Antarctica. It is increasingly available in high bandwidth, both on permanent bases and on temporary field bases. While the primary purpose of the Internet has been to coordinate logistics and the collection of research data, it has also provided scientists with a new way of keeping in touch with distant family members and friends. 
Through various forms of online communication - blogs, podcasts, and live webcasts scientists have been able to share their experiences on a daily basis. Indeed, widespread Internet access has created something of an Antarctic blogosphere, reflecting the diversity of people active in supporting and carrying out research on the continent. Dispatches are published to blogs from most Antarctic bases, with people from a wide range of nationalities and research disciplines contributing. Official blogs associated with specific projects are usually hosted on dedicated websites. Personal blogs, however, predominantly use free services such as Blogger, WordPress, LiveJournal, or TypePad, with only a minority maintaining traditionally styled websites.

An example of one of the more avid writers is Ross Hofmeyr of the AntarcticDoctor blog. Based in the South African SANAE IV base, he has published extensive posts containing text, images, and sometimes videos uploaded to YouTube. Alessia Maggi and JJL maintain the sismordia blog, reporting on their seismologic research at the Concordia base, run by France and Italy. Atle Coward Markussen publishes a personal photoblog from the Norwegian Troll Station, each post containing an incredible range of images and typically accompanied by a single line of commentary. Sudhir Khandelwal became the first Indian to blog from Antarctica when he began publishing Himalayan Adventurer from the Indian Maitri Station. Unlike many other bases, though, Maitri Station has no direct access to the Internet, which has meant that it has to be updated via a shared email address accessible over a slow satellite link.

Antarctic bloggers seem to be self-consciously aware of their (potential) global audience. This leads most of them to write in English, which they perceive to be a more international language than their own, reflecting for some their aspirations to act as citizen journalists or "amateur" science writers. However, there are also numerous blogs in other languages, including French, German, Norwegian, and Spanish. The choice is not always straightforward, though, and depends on the intended audience. Berts Iceposts, penned by Bert from the German base Neumayer Station, epitomizes this politics of language. Having started the blog in English, he switched to German after just two posts "due to severe protests from my german [sic] friends" sent via email. This pressure was also evident on the blog itself, where one comment on his second entry reads: "BITTE SCHREIB DEUTSCH! ...vergiss nicht deine wurzeln im eis! [PLEASE WRITE GERMAN! Do not forget your roots on the ice!]"

Antarctic blogs document a remarkable amount of detail about the extreme conditions in which scientists and support staff operate. Some trivia about life "on the ice" posted in blogs has even been picked up by mainstream news organizations. For instance, a story about some 16,488 condoms being ordered for the McMurdo base was picked up by a New Zealand newspaper in June 2008 and subsequently reported as a curiosity internationally (the condoms are used primarily for sterile storage or transportation of samples). Blogs also provide a continuation of stories in the news, such as that of Sigurd Sande, a Norwegian mechanic who broke his leg while at the top of Mount Buddamagen in October 2008, which was a prominent news story in Norway at the time. His online diary, siggiantarktis.com, although very brief and basic (single HTML page with no comment facility), revealed his personal thoughts on the ordeal. This included an entry on the day of the accident - ending "Glad eg lever [Pleased I am alive]" - and then continued to report updates about his transfer from Antarctica to a Norwegian hospital. 
The most prominent use of Antarctic blogs, regardless of whether they are published in an official or personal capacity, is in connection with educational outreach. This article will now turn to look specifically at how citizen journalism facilitates science education, with particular emphasis on how it provides relatively direct access for global audiences to scientists who are recording the effects of climate change first-hand.

\section{Science blogging as education}

Educational outreach is seen as an integral part of scientific programs operating in the Antarctic and is also strongly encouraged by institutions such as the US National Science Foundation. Traditionally this would involve scientists visiting schools, writing educational books, and possibly appearing on television. However, blogging has increasingly been adopted to complement these activities as it provides a more immediate and interactive form of communicating with targeted and non-targeted audiences.

In many instances, the scientists interviewed for this study were actively blogging for private reasons before the practice was picked up and promoted in a more official capacity. Sarah Fortner, who publishes the blog Crampons and Cornfields, explained that she started blogging to keep "family and friends informed of what I am doing" and to practise her skills in "interpreting the research I am working on (or interested in) to the general public". When she first started reporting from the Antarctic, she was "unaware that this was encouraged":

I have never been directly approached to blog from the Antarctic, but feel that I am in a community that supports communicating with the public. (Sarah Fortner)

Indeed, many of the blogs that are overtly educational in nature are published and maintained in a personal capacity, which reflects the commitment many scientists have to educating and promoting their research to a wider audience. Becky Ball's Polar Soils Blog exemplifies this intricate relationship between Antarctic blogging and education. She describes how it was actually a polar science section of the US second-grade science curriculum that "initially inspired the blog." This collaborative blog has been closely followed by science classes across the United States, with the team actively encouraging teachers to shape how its contributors report on day-to-day activities.

Before leaving for the field, we communicate with school teachers to get an idea of the material that they would find useful to have covered. This helps me choose what topics to blog about throughout the 2-month field season. (Becky Ball)

Beyond reporting daily events, topics are also chosen "in response to questions asked by the classes and the general public" on the blog itself, according to Bell. The first season they blogged from Antarctica, however, "the schools were not very communicative." Instead, she comments, it was "the general public that picked up the blog (the non-target audience)" who were most interactive during this period, with the blog receiving "a lot of questions and comments from a variety of people." This demonstrates that, despite the close connection many of these educational blogs have with school classes, they also have a broader journalistic function for global audiences. "Interaction with readers is what makes the blog fun for us to write", Bell concluded, adding that they had successfully made efforts during the International Polar Year "to establish relationships with more classes in the hopes of having more readers in our target audience with whom to interact". 
During IPY, there were several new projects aimed specifically at raising awareness of the climate-change crisis, such as IGLO (International action on GLObal warming), Inuit Voices: Observations of Environmental Change, and IntSchool (International School Education on Polar issues). These projects were also concerned with finding new ways of communicating science and extending educational outreach. The IPY website, for instance, contained a section with a series of IPY blogs. The blogs were categorized into six different focus areas (atmosphere, ice, land, oceans, people, and space), but could also be filtered by target audiences (educators, participants, and press) or by the approximately 50 different contributors. While people were able to read full entries and submit comments to blogs on the IPY website, they appear not to have been as frequently updated as the main project websites or personal blogs.

For instance, the Norwegian-US Scientific Traverse of East Antarctica - a high-profile, collaborative project to measure climate indicators in the least-explored section of the continent - had published 66 entries to the IPY blog, compared to 135 entries to their online diary on the official project website (November 2008). The project was aimed at investigating the response of East Antarctica to anthropogenic activity and climate change. This is reflected in many of the blog entries where scientists report not only the mechanisms of their research, but also the relevance of samples and data collected for understanding climate change. Several members of the traverse team also contributed articles to personal blogs, while Norwegian public service broadcaster NRK embedded a dedicated reporter and photographer who filed reports on the NRK website, Traversen. "I must be the luckiest journalist in the world!", blogged NRK's Unni Ødegård who accompanied the scientists in Antarctica (cited in Orheim and Ulstein, 2011:181). The success of the project was also reflected in the "large number" of people who went online "to find details of the day's events, photos and video clips", with the website reportedly receiving "over 200000 hits during the most active period" (Orheim and Ulstein, 2011:181).

The Norwegian-US traverse was perhaps the one IPY activity that gained the most attention in mainstream media, though the most significant new initiative in terms of coordinating science writing from the polar regions was undoubtedly the Ice Stories website run by the Exploratorium science museum in San Francisco, California. The latter was intended to provide "a public face for IPY by using the power of contemporary media to bring current research to mass audiences with unprecedented intimacy and immediacy" (Exploratorium, 2008). For the IPY, Ice Stories featured seven citizen journalists from Antarctica in the 2007-2008 season and 13 in the 2008-2009 season, with 9 scientists reporting from the Arctic in 2008 (some scientists continued blogging on the site until the end of 2010). The website combines scientists' dispatches with stunning photographs, podcasts, video content (including a series of live webcasts from the polar regions), and special feature articles providing background on anything from penguins to climate change.

According to the project evaluation (Knight-Williams et al, 2010:81-86), the website received 181 blog posts, which equates to about 7 posts on average per scientist. Of these, some $80 \%$ were posts with images, whilst only $19 \%$ contained video and $10 \%$ contained Soundslides or other forms of audio. The Ice Stories Project Manager, Mark Andrews, noted how the website was getting about 2,500 visitors per week in November 2008. The final report showed a total of 222,831 unique visitors and 569,007 hits to the Ice Stories website in the whole IPY period (Knight-Williams et al, 2010:87). The two most popular posts were "Like No Other: The South Pole Christmas Tree" and "Penguins: Barometers of Climate Change" (2010:92), providing a good demonstration of how the blogs mixed science writing 
with dispatches about the lifeworld in Antarctica. Dialogic interaction between scientists and their audiences were also evident, with the blogs attracting 269 unique comments and the scientists returning 47 responses (2010:86). Scientists also connected with audiences via the explo.tv webcast and in person at the Exploratorium museum.

The Ice Stories website's chief scientist coordinator, Mary Miller, describes the project as having been "successful beyond my wildest imagination." She continues, pointing out that there "are many scientists who are eager to communicate with the public," and the Ice Stories website helps to facilitate their storytelling. Miller explains how the Exploratorium "conducted a six-day workshop with 12-18 scientists in each and trained them in video production, digital photography, audio production, writing and story telling." Media producers and educators from the museum acted as instructors, together with "outside professionals from PBS, NPR, and the San Francisco Chronicle." The training was an important aspect of the Ice Stories project to maximize the impact and to further encourage the scientists to continue with their citizen journalism efforts in the future.

Cassandra Brooks, one of the Ice Stories contributors researching Antarctic toothfish, started with a personal blog from Antarctica in 2006. Her blog was initially written just for friends and family, though "they seemed to get so much out of it" that she "wanted to write for a more widespread audience" when she returned to Antarctica in 2008. She was put in contact with Ice Stories and began blogging for the website. "Science writing appealed to me very much," she explains:

Through writing dispatches I truly grasped the powerful tool that writing is for educating the public.... Once you get people to care about a place, then they will want to protect it and given how the climate is changing most rapidly at the poles, its a critical time for people to take interest. (Cassandra Brooks)

Brooks described Ice Stories as "a really great interactive network" and used the blog to connect directly with remote audiences. "I always try to respond to every comment", she noted, "even when I was at sea". Limited by satellite email from the ship she was stationed on, Brooks would get the Ice Stories team to post her responses to the blog. The blog was effective in facilitating the connection and even after returning home she would "still occasionally get emails from students of all ages asking questions for science projects, school reports or out of their own curiosity". For her, "the response from friends, family and complete strangers was amazing".

Howard Koss, who studies climate variability in historical terms so as to better anticipate future climate change, contributes to three blogs - hosted at Ice Stories, Reach the World, and the dedicated project website - each written with a different target audience in mind so as to engage as many people as possible. Koss views his blogging as a way of bypassing the limitations of more traditional forms of communicating research, thereby helping to reconnect ordinary people with the science behind climate change.

This is my motivation, to make people, from young school children to adults, aware of the need to understand how our global climate will change into the future, and how we as a scientific community are going about it. There has long been a disconnect between the sciences and lay people. I hope to bridge that gap through my blogging efforts. (Howard Koss) 
Whilst the primary purpose of Koss' blogging efforts are to "make people aware of our efforts in obtaining scientific data in Antarctica", he also reported on other aspects of "life on the ice". One example of this was a blog post featuring an interview with the supervisor of the McMurdo Station waste management. The base "recycles nearly $65 \%$ of all waste through stringent sorting methods", Koss noted, "which is one of the highest recycling rates on the globe". For him the story was "important to show as an example of what we as a global community should emulate in our efforts to live more sustainably".

Breana Simmons, who contributes to The World of Nematodes, also stresses the need to connect directly with distant publics. "The purpose of our blog", she commented, "was to make our science more available to people, and especially interact with students" and to make "the general public feel more involved in the science". She argued that the way traditional media frame scientific research, and indeed Antarctica itself, can be problematic:

Teaching young people about Antarctic science, from Antarctica, makes the frozen southern continent a real place, instead of an abstract concept shaped by popular media. Students are incredibly tech-savvy, and publishing a blog seemed like an excellent way to connect with them, and to hold their attention. (Breana Simmons)

The extent to which blogs are successful in achieving these laudable ambitions is difficult to measure by web statistics or online comments alone. Indeed, Becky Ball felt uncertain about how well they were connecting with the schools they were linked to, "until after we returned to the US, when we received drawings and reports about what they learned." Similarly, Mary Miller believes the Ice Stories website has been very successful, with the public having "responded, both on our website through blog comments and our in-person audience for webcasts in the museums."

\section{Unmediated reporting?}

Scientists interviewed as part of this project frequently expressed a desire to connect with ordinary members of the public, often bemoaning the role of mainstream media in providing an unsatisfactory portrayal of their research. Citizen journalism was seen as a way in which they could bypass this mediated process and communicate directly with the public, reporting their research, life on the ice, and - crucially - their first-hand experience of the dramatic climatic changes taking place.

Antarctic bloggers operate in very challenging conditions, however. Perhaps most obviously the scientists are necessarily affiliated with research institutes or science programs and thus are present in Antarctica in a representative capacity. Scientists have no choice but to use the Internet connection provided by the US Antarctic Program (no alternatives are available) and are subsequently bound by guidelines that govern what can or cannot be reported, regardless of the platform it is being published to. Chris Gardner, webmaster and information manager for the McMurdo Dry Valleys LTER (Long Term Ecological Research Program), noted that "the US Antarctic Program has their own set of cybersecurity rules" mostly designed to "target copyright concerns, bandwidth hogs like file sharing and Skype". Moreover, "things like political campaigning are also prohibited". Gardner commented that his own group did not have any rules for publishing blogs, but that they "just try to keep them appropriate". Other groups controlled content more strictly. One communications manager, who wished to remain anonymous, explained how their organization monitors "all personal blogs by going to them on the Internet and reading them," which "has been 
highlighted by comments and action taken when blog entries have not pleased...management."

Several of the bloggers interviewed described an element of self-restraint in the way they publish as a direct consequence of such guidelines or a perceived duty to avoid negative publicity. Comments such as "this has never been a problem for us" were frequently followed up by "mostly using common sense", "we police ourselves in terms of content" or talk of "internal regulation". Tom Crawford of the South Pole Telescope blog claimed he "never personally saw any strict guidelines", but described how bloggers "were gently counseled by those in the know [...] that the National Science Foundation would prefer if we kept content clean and uncontroversial". In a more candid response, another blogger noted that he was "DEFINITELY not publicly documenting any of the inevitable rule bending/breaking that happens when 30 people are living on a tiny outpost 700 miles away from civilization". However, much of this sensitivity was, as Breana Simmons noted, because blogging was perceived as "strictly a scientific, educational endeavor". Care was also needed to adjust content to make it suitable for the respective target audiences, for example public school children. In such instances, the website "administrator interacts with the collaborating teachers to make sure that web content will be appropriate for the respective age groups, and to allow teachers to create a lesson plan around the published entries".

Official or coordinated blogging projects may also have an additional level of editorial control. "We serve as the mediators between the public and the world of research," explains Mary Miller of Ice Stories, "but we let the individual voices of scientists come through without alteration for the most part." They provide feedback on initial story ideas and guide the scientists to provide "content suitable for a public audience."

After a few rounds, the scientists generally get it and their work improves so that we do very little editing (grammar, spelling, and some minor video production or photo sizing is about all we do). (Mary Miller)

The editorial role of sites such as Ice Stories thus contravenes the familiar sense of blogs being raw, impressionistic, and - most important - unedited. However, none of the scientists interviewed who were affected by this level of mediation felt that it posed a serious problem in and by itself. On the contrary, they were grateful for what they thought helped to sharpen their message, enabling them to be better placed to report on their research and life on the ice.

\section{Conclusion}

The climate-change crisis resonates throughout the Antarctic blogosphere as the bloggers strive to bear witness to the dramatic impact of global warming unfolding around them. Even scientists whose research is not directly related to climate change frequently publish accounts describing how they are observing the transformation first-hand. This emergent form of science reporting provides an important contrast to traditional forms of journalism, where the process of climate change is a difficult fit for conventional, event-led news agendas.

Even blog posts about day-to-day scientific activities attract a sizeable audience, with readers evidently mesmerized by the exotic and extreme nature of this remote location. Such personal narratives help to further personalize the scientists and their work. For the lay 
reader, the style of writing adopted by the majority of these citizen journalists makes the scientific arguments more accessible, not to mention more interesting. Readers' comments, posted to the blogs, frequently make statements of admiration and support, while also asking questions about the entries themselves. As highlighted in this article, scientists often respond to such feedback directly, either as follow-up comments or in new posts published at a later stage. The blogs therefore facilitate a dialogic interaction that goes some distance to bridge the gap between scientists and the public. This was echoed by the official Lessons and Legacies of the International Polar Year 2007-2008 report, which found that:

"The education and outreach efforts during IPY raised the bar for the quality of scientist interactions with teachers, students, and the public in ways that increase public understanding of science." (Brigham-Grette and Bindschadler, 2012:25)

Yet the IPY had a predefined timespan and its International Programme Office finally closed in September 2010 and, whilst there is still a bustling Antarctic blogosphere, many of the blogs connected with the IPY are no longer being updated. Nevertheless, these initiatives have been transformative beyond the initial publication of blogs. The Ice Stories project, for example, "not only allowed the public to connect and follow researchers, it taught the researchers communication skills that they could take on to future projects, fostering a culture of active science outreach." (Provencher et al, 2011:37). According to

Salmon et al. (2011), the success of "the IPY science education, outreach and communication $[\ldots]$ derived primarily from international collaboration and cooperation, from careful cultivation of a global community of enthusiastic volunteers, and from creative use of free technologies." Moreover, in their view, "The success of these activities also shows how science communication can, and indeed must, function in the modern multimedia environment" (Salmon et al., 2011:283).

Indeed while the new form of citizen journalism or science writing discussed in this article helps to raise people's awareness of the climate-change crisis, it also signals an important way in which mainstream environmental reporting can be reinvigorated. Scientists' blogs, with their interactive forms of storytelling providing relatively direct access to expert knowledge, represent a remarkable resource, the potential of which is only now being recognized.

\section{Acknowledgment}

The author wishes to thank the many Antarctic bloggers, including those not cited here, who took part in e-interviews and provided background information for this article.

\section{References}

Allan, S. (2009). The future of science journalism. Journalism, 10(3), 280-282.

Allan,

"Making science newsworthy: exploring the conventions of science journalism." In

R. Holliman, J. Thomas, S. Smidt, E. Scanlon, \& L. Whitelegg (Eds.), Investigating science communication in the information age: implications for public engagement and popular media. Oxford: Oxford University Press.

Ashlin, A. (2006). SCIENCE COMMUNICATION: Enhanced: Environmental Science Adrift in the Blogosphere. Science, 312(5771), 201-201.

Batts, S. A., Anthis, N. J., \& Smith, T. C. (2008). Advancing Science through Conversations: Bridging the Gap between Blogs and the Academy. PLoS Biology, 6(9), e240. 
Boykoff, M.T., \& Boykoff, J.M. (2007) "Climate change and journalistic norms: a casestudy of US mass-media coverage." Geoforum, 38(6), 1190-1204.

Brigham-Grette, J., Bindschadler, A. R. (eds) (2012) Lessons and Legacies of the International Polar Year 2007-2008, Washington: The National Academies Press.

Bubela, T. et al. (2009), Science communication reconsidered, Nature Biotechnology 27(6), 514-518.

Byrd, R. E. \& Gould, L. M. (1928) Little America, Aerial Exploration in the Antarctic. New York: G. P. Putnam's Sons.

Carvalho, A. (2007) "Ideological cultures and media discourses on scientific knowledge: rereading the news on climate change." Public Understanding of Science, 16(2), 223243.

Carvalho, A., \& Burgess, J. (2005) "Cultural circuits of climate change in U.K. broadsheet newspapers, 1985-2003.” Risk Analysis, 25(6), 1457-1469.

Colson, V. (2011). Science blogs as competing channels for the dissemination of science news. Journalism, 12(7), 889-902.

Davis, L. S. (2008). Popularizing Antarctic science: impact factors and penguins. Aquatic Conservation: Marine and Freshwater Ecosystems, 17(S1), S148-S164.

Exploratorium (2008) "Exploratorium's ice stories: dispatches from polar scientists." IPY. http://www.ipy.org/index.php?/ipy/detail/ice_stories/, consulted November 2008.

Gavin, N.T. (2007) "Global warming and the British press: the emergence of an issue and its political implications." Elections, Public Opinion and Parties. University of the West of England, Bristol: Political Studies Association.

Horrigan J. B. (2006) The Internet as a resource for news and information about science. Washington, DC: Pew Internet \& American Life Project.

Horrigan, J. B. (2008) "Science \& cyberspace: what user behavior means for science educators." Leadership Initiative in Science Education Conference. Philadelphia, PA: Chemical Heritage Foundation.

Ki-moon, B. (2007) Antarctica, 9 November 2007 - Secretary General's Statement on Antarctica. United Nations.

Knight-Williams, V., Williams Jr., D., Meyers, C., Grinberg, O., Sraboyants, T., Chan, E., and Tower, D. (2010) Ice Stories Summative Evaluation: Compilation of Professional and Public Audience Evaluation Reports. Knight Williams Inc.

Neverla, I. (2008) "The IPCC-reports 1990-2007 in the media. A case-study on the dialectics between journalism and natural sciences." ICA-Conference, "Global Communication and Social Change." Montreal: International Communications Association.

Orheim, O. and Ulstein, K. (eds) (2011) The Norwegian Contribution: International Polar Year 2007-2008. Oslo: The Research Council of Norway.

Provencher J, Baeseman J, Carlson D, Badhe R, Bellman J, Hik D, Huffman L, Legg J, Pauls M, Pit M, Shan S, Timm K, Ulstein K, Zicus S (2011) Polar Research Education, Outreach and Communication during the fourth IPY: How the 2007-2008 International Polar Year has contributed to the future of education, outreach and communication. Paris: International Council for Science (ICSU).

Russell, C. (2008) "Climate change: now what? A big beat grows more challenging and complex." Columbia Journalism Review, July/August, n.p.

Salmon, R. A., et al. (2011) "Education, outreach and communication during the International Polar Year 2007-2008: stimulating a global polar community." The Polar Journal, 1(2), 265-285.

Shanahan, M. C. (2011) "Science blogs as boundary layers: Creating and understanding new writer and reader interactions through science blogging". Journalism, 12(7), 903-919. 
The Antarctic Treaty (1959) The Antarctic Treaty. Washington, D. C.: Antarctic Treaty Secretariat.

The Norwegian Nobel Committee (2007) The Nobel Peace Prize for 2007. Nobelprize.org. Trench, B. (2007) "How the Internet changed science journalism." In M.W. Bauer \& M. Bucchi (Eds.), Journalism, science and society: science communication between news and public relations. New York and London: Routledge.

Wilson, K.M. (2000) "Communicating climate change through the media: predictions, politics and perceptions of risk." In S. Allan, B. Adam, \& C. Carter (Eds.), Environmental risks and the media (pp. 201-217). London: Routledge.

\section{Notes}

\footnotetext{
i The 'year' actually runs from March 2007 - March 2009 'to ensure that researchers get the opportunity to work in both polar regions or work summer and winter if they wish' (International Polar Year, 2005).

ii Territorial claims are not widely recognised, but have variously been put forth by Argentina, Australia, Chile, France, New Zealand, Norway, and the United Kingdom - in total covering an estimated four thirds of the continent (some claims overlap) - whilst the US and Russia have both reserved the right to make claims in the future. Antarctica uniquely contains the only landmass on Earth not claimed by any country - the area between 90 degrees west and 150 degrees west.

iii With the support of the US Navy, the New York Times and several other corporations, he set up a system containing 24 transmitters and 31 receivers, and a communications team containing five radio engineers. Byrd recalled how 'this single department received more attention than any other, for our program called for the most elaborate system of communication ever proposed in a Continent where radio conditions are notoriously bad' (Byrd and Gould, 1928:36).
} 